\title{
Analysis on different shape of textile antenna under bending condition for GPS application
}

\author{
N. I. Zaidi ${ }^{1}$, M. T. Ali ${ }^{2}$, N. H. Abd Rahman ${ }^{3}$, M. F. Yahya ${ }^{4}$, M. S. Amin Nordin ${ }^{5}$ \\ 1,2,3,5 Antenna Research Centre (ARC), Faculty of Electrical Engineering, Universiti Teknologi MARA, \\ 40450 Shah Alam, Selangor, Malaysia \\ ${ }^{4}$ Faculty of Applied Science, Universiti Teknologi MARA, 40450 Shah Alam, Selangor, Malaysia
}

\begin{tabular}{l} 
Article Info \\
\hline Article history: \\
Received Dec 15, 2019 \\
Revised Mar 3, 2020 \\
Accepted Apr 4, 2020 \\
\hline
\end{tabular}

\section{Keywords:}

Bending

Conductive fabric

GPS

Textile antenna

Wearable antenna

\begin{abstract}
In this paper, three antennas with different designs, which are square, circle and edgy patch (flower) were simulated and fabricated. The experiment was carried out to study the effects of bending on these three different shapes of antennas. Two bending conditions which are H-plane and E-plane were used. The antenna was designed to resonate at $1.575 \mathrm{GHz}$ for GPS application and to be incorporated with human arm. Thus, the bending angle was specified to be $135^{\circ}$ which is about the size of a typical human arm. As the paper focusing on the bending effects only, the characteristic of the bending structure was set to be equal to the air, with $\varepsilon_{r}=1$. The antenna characteristics such as gain, resonant frequency and radiation pattern were analyzed for these three shapes of antennas. As a result, the shape of the radiating patch has significant impact on the antenna performance under bending conditions. Based on the comparison of E-plane and H-plane data, the edgy shape was found to be more affected in term of gain performance as compared to other shapes. Bending on E-plane has shown severe degradation in antenna gain performance, whereby at H-plane, significant improvement in gain was observed.
\end{abstract}

This is an open access article under the CC BY-SA license.

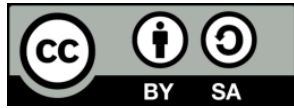

\section{Corresponding Author:}

\section{N. H. Abd Rahman}

Antenna Research Centre, Faculty of Electrical Engineering,

Universiti Teknologi MARA,

Shah Alam, Selangor, 40450 Malaysia.

Email: nurulhuda0340@uitm.edu.my

\section{INTRODUCTION}

Wearable technology has experience a slow growth in the market since 1970s. Until recently, the market for wearable technologies has dramatically increased from the popularity of fitness tracker and smart watch. Now, smart clothing such as textile antenna or e-textile became the sensation for wearable technologies as they have a great potential due to their low mass, physical flexibility, and ability to be embedded on garment $[1,2]$. E-textile is a conducting fabric that supports the idea of wearable computing or electronic device that is integrated into garment. This platform can be applied in some application such as medical and military as it enables wireless communication network including tracking and navigation, health monitoring, public safety and also can work for entertainment [3-7]. Textile antenna is developed to be a part of clothing. Therefore, to make it more practical, flexible and suitable to be worn, a study on fabric material for antenna substrate such as felt, cotton, jeans, and polyester is done [8-10]. Many studies related to textile antennas such as materials and types of patch used [11-13], sewing and embroidery effects [14, 15], Electro-Textile [16, 17], water and moisture effects [18], specific absorption rate (SAR) by human [19, 20], bending effects $[21,22]$ and simulation of actual fabric [23] is developed in order to enhance the technology. 
Since textile antenna is placed on clothing, it is impossible for the antenna to remain flat on cloth as we make movement every time. Thus, it is important to study the effect of bending on antenna performance.

Previously, researchers have studied the antenna performances on flat condition [24-26]. In this paper, three designs of textile antenna with different shape of patches are presented. The first antenna is a simple square patch antenna, then circle patch antenna and lastly the edgy antenna which illustrate the flower. The antennas are simulated and measured under the E-plane and H-plane bend conditions. To demonstrate the bent condition, a cylindrical foam with $42.5 \mathrm{~mm}$ radius and permittivity of $1\left(\varepsilon_{r}=1\right)$ is used. The radius of the cylindrical foam gives a bending angle of approximately $135^{\circ}$, which represents the radius of a human arm. Here, the dielectric effects of the human arm are preliminary ignored to analyze the bending effect to the antenna performance. The performance of the antenna is analyzed and the effect of the bending on each antenna shape is studied. The conductive fabric used is the custom-made e-textile that was developed in our lab facilities.

\section{RESEARCH METHOD}

This section will be divided into few sub topics which are conductive yarn, conductive fabric (e-textile), and antenna design.

\subsection{Conductive yarn}

As in previous work [27], two types of yarn which are copper covered yarn and copper core sheathed yarn are developed and tested for its performance. Copper covered yarn is a polyester yarn that is twisted around by copper yarn, while copper core sheathed yarn is a copper yarn that is wrapped around by polyester yarn. From the results, copper covered yarn has a superior performance as compared to copper core sheathed yarn due to its yarn characteristics. Copper covered yarn has high composition of copper yarn, high number of conductive yarn in $1 \mathrm{~cm}^{2}$ of fabric and also small in size. Therefore, copper covered yarn as shown in Figure 1 is presented in the experiment.

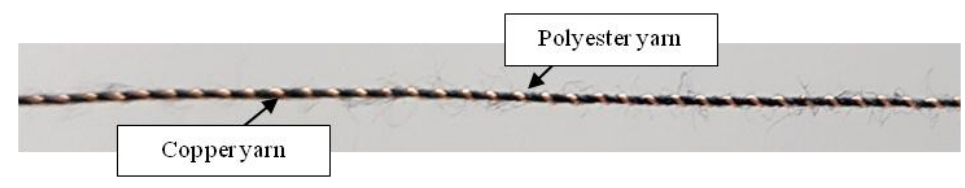

Figure 1. Copper covered yarn

\subsection{Conductive fabric}

By employing a previous conductive yarn, the conductive fabric is developed by using SULZERTEXTILE G6300 Rapier Weaving machine. The conductive yarns are interlaced with non-conductive yarn in order to make it more comfortable to a wearer. As reported in [28], weaving techniques influenced the antenna performance, thus, three weaving techniques which are plain, satin and twill are investigated. The results were explained through dielectric loss mechanism and it was observed that satin weaving technique has the best gain performance since the ratio of copper in metallic face is greater than plain and twill. Hence, satin weaving fabric as in Figure 2 is applied for the next antenna designed.

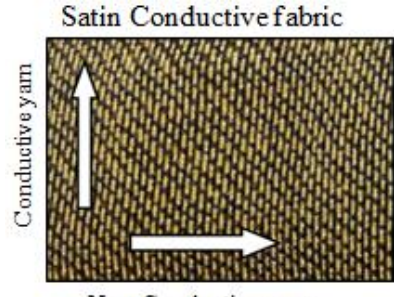

Non-Conductive yarn

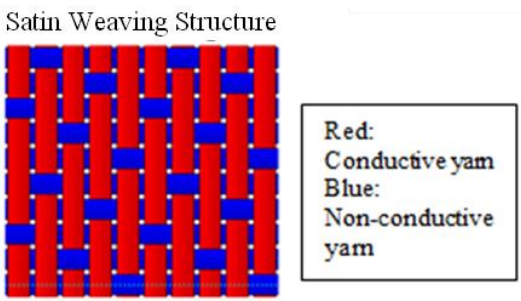

Figure 2. Satin weaving pattern [24]

\subsection{Antenna design}

Three different antenna designs are simulated and fabricated. A simple square patch textile antenna represents design 1. Then, a circular textile antenna represents design 2 and a flower textile antenna will 
represent design 3. The specification of the antenna designs is explained in Table 1. Figures 3 and 4 represent the geometry of the antenna and the detailed dimensions of antenna design 1, 2, and 3.

Table 1. Antenna design specification

\begin{tabular}{ll}
\hline Features & Specifications \\
\hline Frequency of operation & $1.575 \mathrm{GHz}$ \\
Patch & E-textile-Copper covered fabric $(\sigma=30200 \mathrm{~S} / \mathrm{m})$ \\
& Thickness $=0.36 \mathrm{~mm}$ \\
Substrate & Polyester $(\varepsilon r=1.36)$ \\
& Thickness $=1.44 \mathrm{~mm}$ \\
Ground & Fully copper \\
& Thickness $=0.035 \mathrm{~mm}$ \\
Feeding method & Coaxial probe (SMA $50 \Omega$ connector) \\
\hline
\end{tabular}

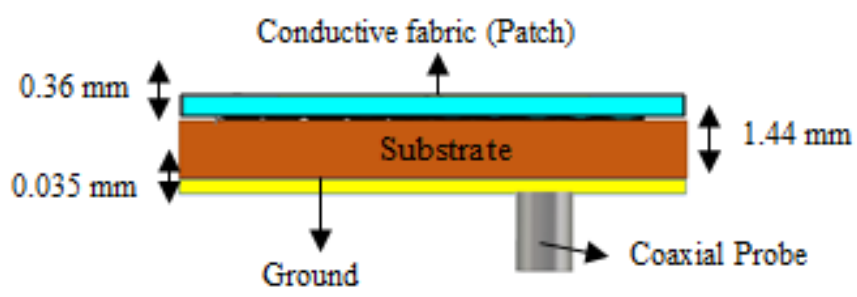

Figure 3. Geometry of antenna design

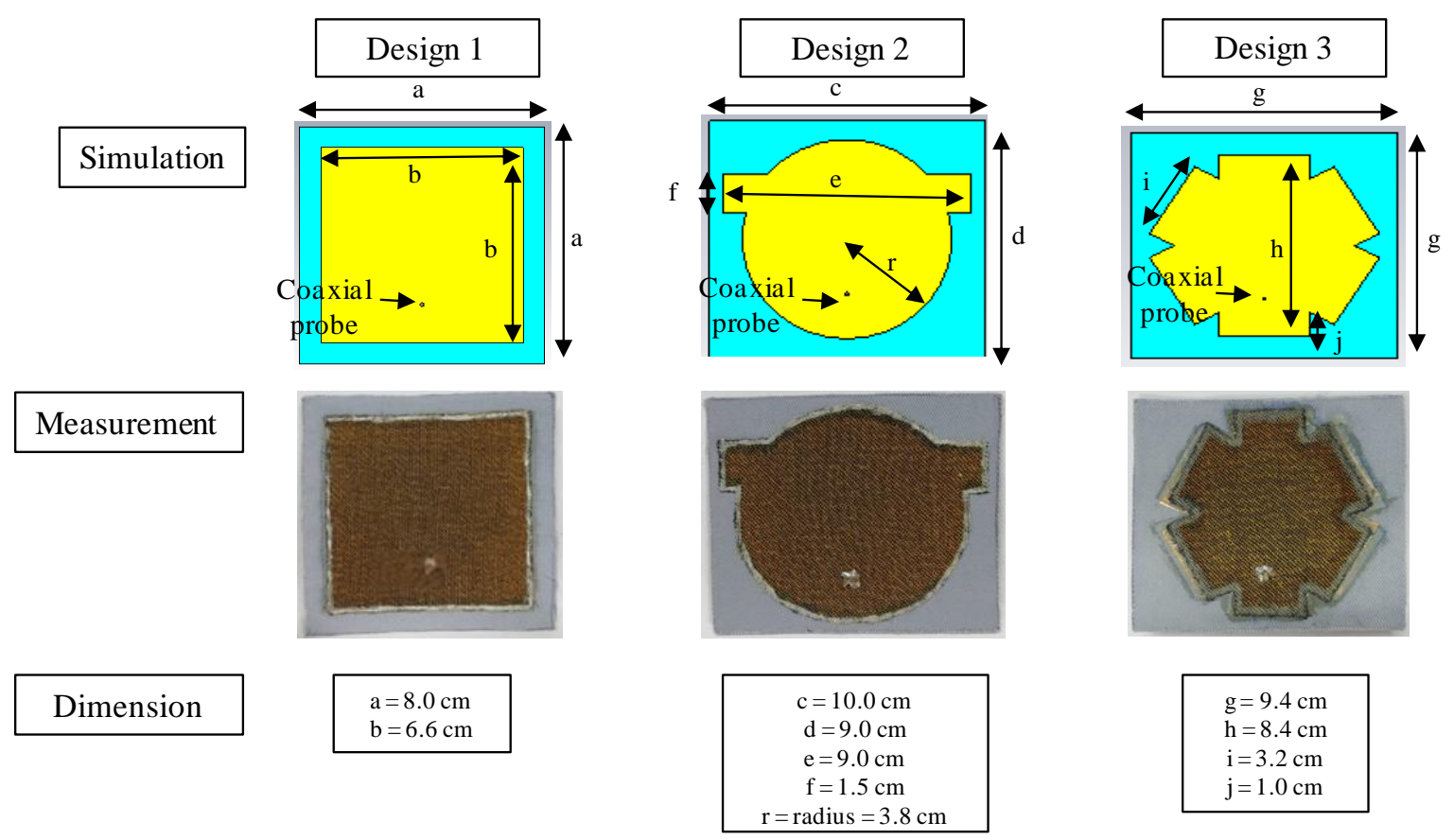

Figure 4. Dimension for antenna design 1 (square patch textile antenna), design 2 (circular patch textile antenna), and design 3 (flower patch textile antenna)

\section{RESULTS AND DISCUSSION}

This section will discuss the bending effect of three shapes of textile antennas under E-plane and H-plane bending condition. The performance of the antennas will be analyzed in terms of resonant frequency, gain and radiation pattern. The simulation is performed using CST microwave software and the fabricated antennas are measured in anechoic chamber OTA-500. Figure 5 shows the experimental setup for the measurement of antenna in bent condition. 


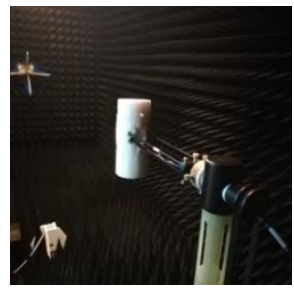

H-plane setup

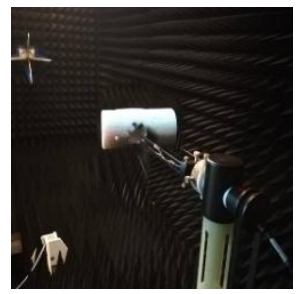

E-plane setup

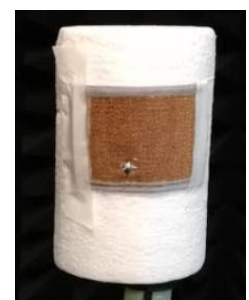

Design 1

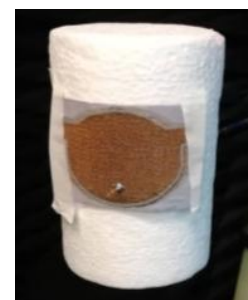

Design 2

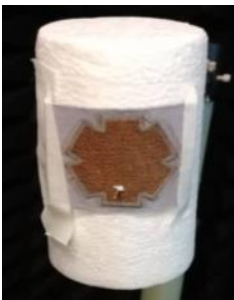

Design 3

(a)

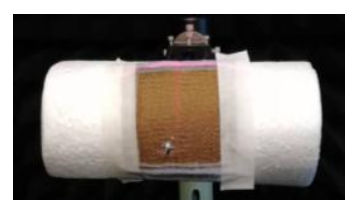

Design 1

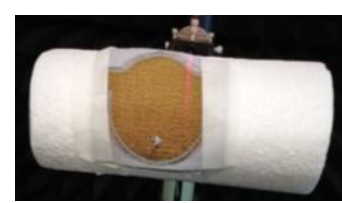

Design 2

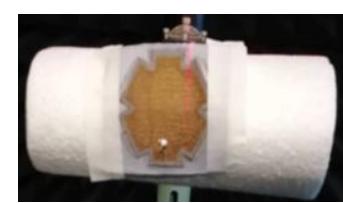

Design 3

(b)

Figure 5. Antenna on H-plane and E-plane bent condition, (a) H-plane bent condition,

(b) E-plane bent condition

Figure 6 presents the results of resonant frequency and return loss of the three antennas with respect to bending effects at H-plane and E-plane. From the results, the resonant frequency for all antennas is slightly shifted when the antenna is bent. Theoretically, the antenna changes its effective length when the antenna is bent. When the bending angle of the antenna increases, the effective length is decreased and the resonant frequency will shift to a higher band [22]. As seen in Figure 7, the antenna is highly shifted when the antenna is bent along the E-plane. This is because the bending occur at the radiating element of the antenna. For return loss, it is normal to have increment in magnitude when the antenna is bent. From the results, all antennas have maintained the return loss of under $-10 \mathrm{~dB}$ after bending is applied.

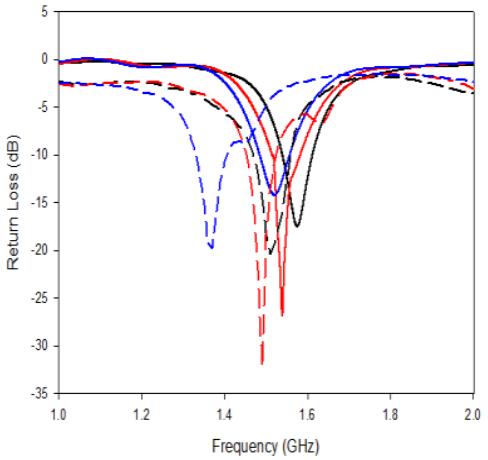

(a)

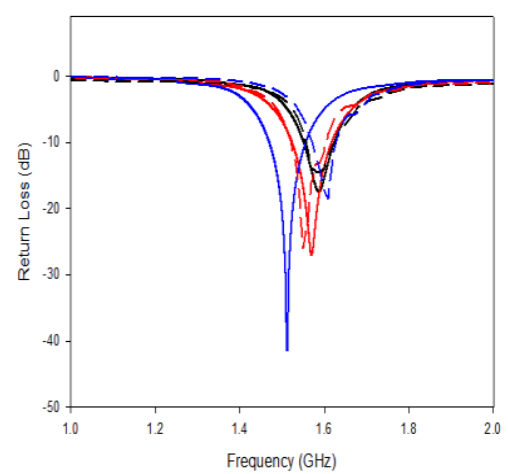

(b)

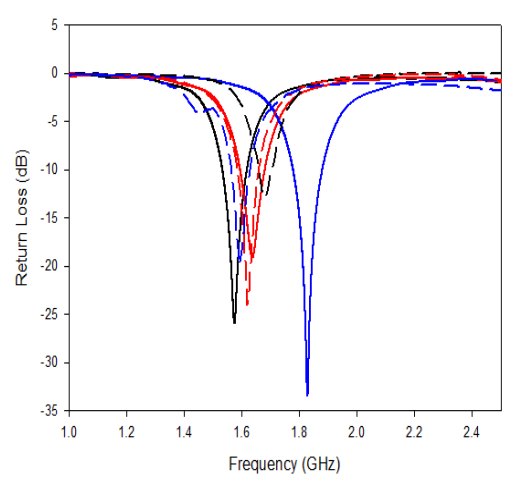

(c)
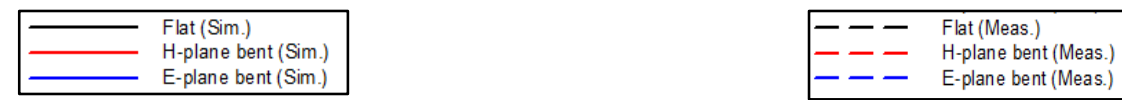

Figure 6. Resonant frequency and return loss of all antennas, (a) Design 1, (b) Design 2, (c) Design 3

As for radiation pattern presented in Figure 7, the investigation shows that when bending is applied on E-plane the side lobe becomes larger, and when bending is applied on H-plane the side lobe has decreased. Figure 8 explained the current flow of the situation expressed in Table 2. In term of gain, the result in Table 2 shows that the gain of the antenna is increased when it is bent along H-plane. Meanwhile, 
the gain is dramatically decreased when the antenna is bent towards E-plane. So, when the antenna is in flat condition, the current is distributed equally. However, when the antenna is bending in H-plane condition, the current will accumulate at the bend side. Thus, higher magnetic field appears and causing the antenna to be more directional which has resulted in the increase in gain and reduced in side lobe of radiation pattern. However, when the antenna is bent towards E-plane, the current will be distributed to side, less current accumulate at the center. Hence, the gain decreased and more side lobe form on radiation pattern.

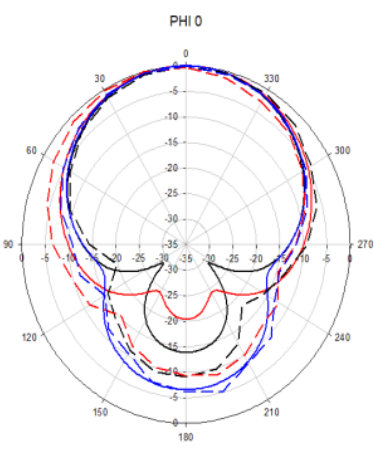

(a)

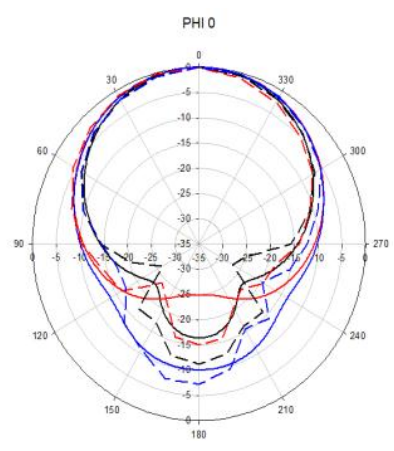

(b)

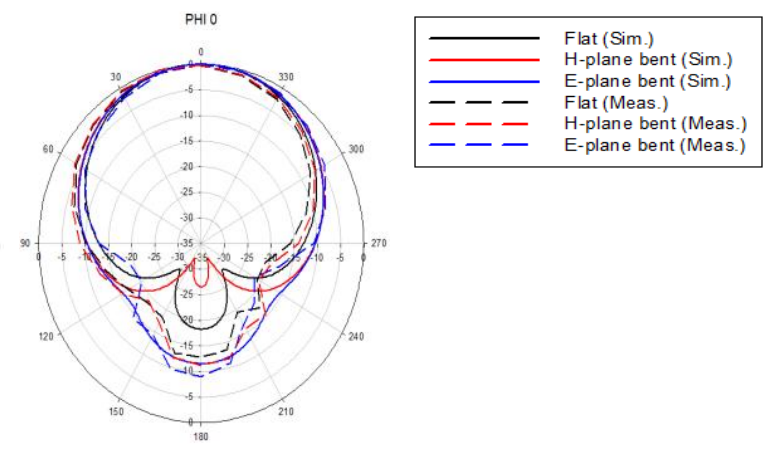

(c)

Figure 7. Radiation pattern of all antenna (a) Design 1, (b) Design 2, and (c) Design 3

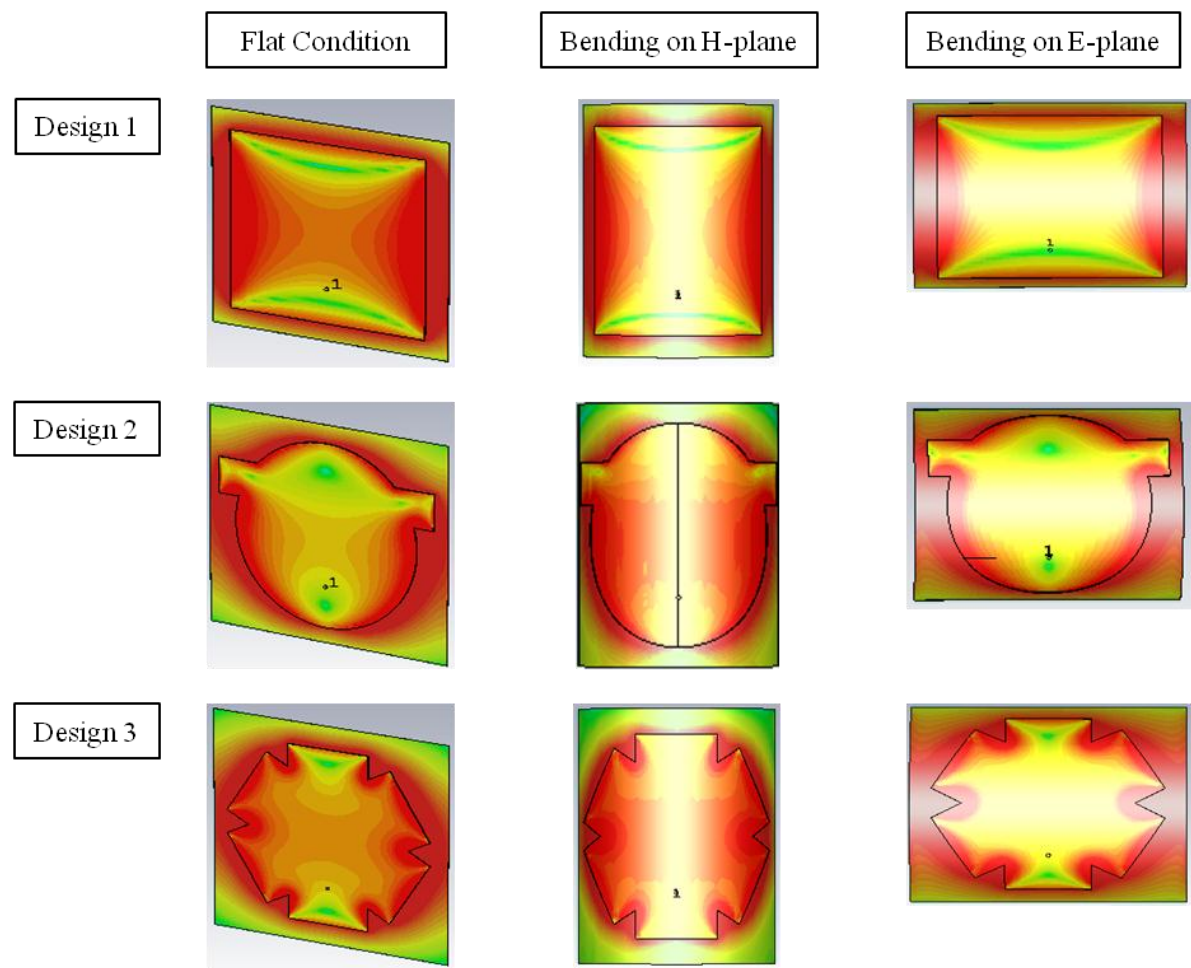

Figure 8. Current distribution of the flat antenna and bent antenna in the H-plane and the E-plane bending conditions

Table 2. Gain performance of antenna design 1.2 and 3 towards bent condition

\begin{tabular}{|c|c|c|c|c|c|c|}
\hline \multirow[t]{3}{*}{ Type of antennas } & \multicolumn{6}{|l|}{ Gain $(\mathrm{dB})$} \\
\hline & \multicolumn{2}{|l|}{ Flat antenna } & \multicolumn{2}{|l|}{ Bending on H-plane } & \multicolumn{2}{|c|}{ Bending on E-plane } \\
\hline & Simulation & Measurement & Simulation & Measurement & Simulation & Measurement \\
\hline Design 1 & 1.21 & 1.15 & 1.43 & 1.29 & -0.24 & -0.96 \\
\hline Design 2 & 1.58 & 1.39 & 1.96 & 1.55 & -0.15 & -0.71 \\
\hline Design 3 & 1.60 & 1.43 & 2.68 & 2.52 & -1.8 & -3.23 \\
\hline
\end{tabular}


From Table 2, it is also noticed that the greatest increment and decrement in the gain occurs at antenna design 3 (flower). Based on the observation, this situation happens due to the shape of the antenna used. Design 3 implements flower shape which actually has more edgy shape compared to design 1 and 2 . When edgy design is applied on antenna, its effect on bending seems to be more obvious. The measured gain antenna for design 3 showed the highest increment in H-plane and became severe in E-plane. Fabrication error may also contribute to the worst antenna performance as a lot of edge to be cut manually and soldering also affect the antenna performance [29]. As compared to design 1 and 2, the increment and decrement of gain are not obvious even in bending condition.

\section{CONCLUSION}

The analysis on the effects of bending towards different shape of antenna design is done. The shape of antenna has significant influence to the antenna performance. The edgy the antenna the more obvious its increment and decrement in gain. This condition actually shows that the antenna is not stable, since the performance can increase and decrease drastically. So in order to design a textile antenna, it is preferred to use antenna with less edges. On the other hand, by implementing a simple and less edge design, mechanical error such as fabricating error could be reduced since the fabric is manually cut and fabricate. Through this study, it is realized that bending condition will also influence the antenna performance. Bending along the H-plane could increase the gain since the current accumulates at the center of the bent side and produces high magnetic field which will enable the gain to increase and the antenna will be more directive. However, bending on E-plane will decrease the antenna gain and directivity, as the current accumulates along the E-plane will disperse to the side of antenna. Therefore, in real application, it is crucial to let the antenna to bend along the H-plane only. In terms of frequency, bending does not affect much at the resonant frequency in H-plane bent. As for return loss, they are all below $-10 \mathrm{~dB}$ even after bending is applied. In conclusion, from the results and analysis, textile antenna is seen to be tolerable towards the bending and suitable to be worn.

\section{ACKNOWLEDGEMENTS}

This work was supported by the Malaysia Ministry of Education through the Fundamental Research Grant Scheme (FRGS/1/2018/TK04/UITM/02/25). The authors would also like to give appreciation towards Antenna Research Centre (ARC), Faculty of Electrical Engineering, Universiti Teknologi MARA, (UiTM) Shah Alam and also Textile Research Group, Faculty of Applied Science, Universiti Teknologi MARA (UiTM) Shah Alam for providing facilities to conduct the present research.

\section{REFERENCES}

[1] A. Yadav, V. K. Singh, M. Chaudhary, and H. Mohan, "A review on wearable textile antenna," Journal of Telecommunication, Switching System and Networks, vol. 2, no. 3, pp. 37-41, 2015.

[2] S. Purohit and F. Raval, "A review on wearable-textile patch antenna," International Journal of Scientific \& Engineering Research, vol. 4, no. 12, pp. 696-702, 2013.

[3] E. G. Lim, Z. Wang, J. C. Wang, M. Leach, R.Zhou, C-U. Lei, and K. L. Man, "Wearable textile substrate patch antenna," Engineering Letters, vol. 22, pp. 94-101, 2014.

[4] B. Xu, R. Eike, A. Cliett, R. Cloud, and Y. Li, "A short review of textile applications in antenna design," Trends in Textile Engineering \& Fashion Technology, vol. 1, no. 5, pp. 119-121, 2018.

[5] G. Christina, A. Rajeswari, M. Lavanya, J. Keerthana, K. Ilamathi, and V. Manoranjitha, "Design and development of wearable antennas for tele-medicine applications," International Conference on Communications and Signal Processing, Melmaruvathur, pp. 2033-2037, 2016.

[6] H. Lee, J. Tak, Y. Hong, and J. Choi, "Design of an all-textile antenna integrated in military beret for GPS/RFID applications," 2016 International Symposium on Antennas and Propagation ISAP, Okinawa, pp. 982-983, 2016.

[7] M. Niswar, M. Nur, A. A. Ilham, and I. Mappangara, "A low cost wearable medical device for vital signs monitoring in low-resource settings," International Journal of Electrical and Computer Engineering IJECE, vol. 9, no. 4, pp. 2321-2327, 2019.

[8] M. S. A. Nordin, N. H. A. Rahman, M. T. Ali, A. A. S. Ahmad, and M. R. Ahmad, "Performance comparison of various textile composition and structure through full-wave electromagnetic simulation and measurement," Journal of Telecommunication, Electronic and Computer Engineering, vol. 10, no. 1-6, pp. 55-58, 2018.

[9] A. Khan and R. Nema, "Analysis of five different dielectric substrates on microstrip patch antenna," International Journal of Computer Applications, vol. 55, no. 14, pp. 40-47, 2012.

[10] A. Y. I. Ashyap, Z. Z. Abidin, S. H. Dahlan, S. Mohd Shah, H. A. Majid, Y. S. Khee, and N. A. Malek, "A wearable antenna based on fabric materials with circular polarization for body-centric wireless communications," Indonesian Journal of Electrical Engineering and Computer Science (IJECS), vol. 18, no. 1, pp. 335-342, April 2020. 
[11] P. M. Potey and K. Tuckley, "Design of wearable textile antenna with various substrate and investigation on fabric selection," 2018 3rd International Conference on Microwave and Photonics ICMAP, Dhanbad, pp. 1-2, 2018.

[12] S. Zhang, R. Seager, A. Chauraya, W. Whittow, and Y. Vardaxoglou, "Textile manufacturing techniques in RF devices," 2014 Loughborough Antennas and Propagation Conference LAPC, Loughborough, pp. 182-186, 2014.

[13] A. A. S. Ahmad Shah, N. H. A. Rahman, M. T. Ali, M. R. Ahmad, and M. S. A. Nordin, "Investigation on various structural compositions of textile-integrated antenna," In Advanced Electromagnetics Symposium, 2017.

[14] A. Tsolis, W. G. Whittow, A. A. Alexandridism and J. C. Vardaxoglou, "Embroidery and related manufacturing techniques for wearable antennas: challenges and opportunities," Electronics Journal, vol. 3, no. 2, pp. 314-338, 2014.

[15] N. J. Ramly, M. K. A Rahim, N. A Samsuri, and H. A. Majid, "Embroidery leaf shape dipole antenna performances and characterisation," International Journal of Electrical and Computer Engineering (IJECE), vol. 7, no. 3, pp. 1467-1472, June 2017.

[16] A. Priya, A. Kumar, and B. Chauhan, "A review of textile and cloth fabric wearable antennas," International Journal of Computer Applications, vol. 116, no.17, pp. 1-5, 2015.

[17] A. Asghar, M. R. Ahmad, M. F. Yahya, M. T. Ali, A. A. Ab Aziz, N. H. Abd Rahman, and M. Kashif, "An alternative approach to design conductive hybrid cover yarns for efficient electromagnetic shielding fabrics," Journal of Industrial Textiles, vol. 48, no. 1, pp. 38-57, 2018.

[18] M. A. R. Osman, M. K. A. Rahim, N. A. Samsuri, M. K. Elbasheer, and M. E. Ali, "Textile UWB antenna bending and wet performances," International Journal of Antennas and Propagation, vol, 2012, pp. 1-12, 2012.

[19] N. H. Abd Rahman, Y. Yamada, and Muh. S. Amin Nordin, "Analysis on the effects of the human body on the performance of electro-textile antennas for wearable monitoring and tracking application," Materials, vol. 12, no. 10, pp. 1-17, 2019.

[20] R. Manikonda, R. Valluri, and M. R. Prudhivi, "J-slot EBG structure for SAR reduction of dual band j-slot textile antenna," Indonesian Journal of Electrical Engineering and Computer Science (IJECE), vol. 12, no. 2, pp. 794-802, Nov 2018.

[21] L. Z. Tung, G. A. Mahdiraji, and L. C. Ping, "Comparative Study between planar and bent antenna characterization," MATEC Web of Conferences, vol. 152, pp. 1-11, 2018.

[22] L. Song and Y. Rahmat-Samii, "A systematic investigation of rectangular patch antenna bending effects for wearable applications," in IEEE Transactions on Antennas and Propagation, vol. 66, no. 5, pp. 2219-2228, 2018.

[23] N. I. Zaidi, M. T. Ali, N. H. A. Rahman, M. F. Yahya, M. S. A. Nordin, and A. A. S. A. Shah, "Accurate simulation of fabric and analysis of antenna performance on different substrate materials," 2018 IEEE International RF and Microwave Conference RFM, Penang, Malaysia, pp. 77-80, 2018.

[24] N. Amaro, C. Mendes, and P. Pinho, "Bending effects on a textile microstrip antenna," 2011 IEEE International Symposium on Antennas and Propagation APSURSI, Spokane, WA, pp. 282-285, 2011.

[25] D. Ferreira, P. Pires, R. Rodrigues, and R. F. S. Caldeirinha, "Wearable Textile antennas: Examining the effect of bending on their performance.," in IEEE Antennas and Propagation Magazine, vol. 59, no. 3, pp. 54-59, June 2017.

[26] A. Mersani, L. Osman, and J. Ribero, "Effect of bending on the characteristics of a coplanar textile antenna," 2018 18th Mediterranean Microwave Symposium MMS, Istanbul, pp. 255-257, 2018.

[27] N. I. Zaidi, M. T. Ali, N. H. A.Rahman, M. S. Amin, A. A. S. Ahmad Shah, and M. F. Yahya, "Comparison of copper covered and copper core sheath yarn for the fabrication of textile antenna," International Journal of Electrical And Electronic Systems Research, vol. 13, Dec 2018.

[28] N. I. Zaidi, M. T. Ali, N. H. A. Rahman, M. S. Amin Nordin, A. A. S. Ahmad Shah, and M. F. Yahya, "A comprehensive study of weaving structure and its impact on textile antenna for WBAN application," 2019 13th European Conference on Antennas and Propagation EuCAP, Krakow, Poland, pp. 1-5, 2019.

[29] R. Garg, P. Bhartia, I. Bahl, and A. Ittipiboon, "Microstrip antenna design handbook," Library of Congress Cataloging-in-Publication Data, Artech House Inc., 2001. 